\title{
openheart Case series, contemporary review and imaging guided diagnostic and management approach of congenital pericardial defects
}

\author{
Mohamed Khayata (D) , ${ }^{1}$ Saqer Alkharabsheh, ${ }^{2}$ Nishant P Shah, ${ }^{2}$ Beni Rai Verma, ${ }^{1}$ \\ James L Gentry, ${ }^{2}$ Mathew Summers, ${ }^{2}$ Bo Xu, ${ }^{2}$ Craig Asher, ${ }^{3}$ Allan L Klein ${ }^{2}$
}

To cite: Khayata M, Alkharabsheh S, Shah NP, et al. Case series, contemporary review and imaging guided diagnostic and management approach of congenital pericardial defects. Open Heart 2020;7:e001103. doi:10.1136/ openhrt-2019-001103

Received 31 May 2019 Revised 7 November 2019 Accepted 12 December 2019
Check for updates

C) Author(s) (or their employer(s)) 2020. Re-use permitted under CC BY-NC. No commercial re-use. See rights and permissions. Published by BMJ.

${ }^{1}$ Internal Medicine, Cleveland Clinic, Cleveland, Ohio, USA ${ }^{2}$ Cardiology, Cleveland Clinic, Cleveland, Ohio, USA

${ }^{3}$ Cardiology, Cleveland Clinic Florida, Weston, Florida, USA

Correspondence to Allan L Klein; kleina@ccf.org

\section{ABSTRACT}

Objective Congenital pericardial defect (CPD) is a rare entity with an estimated frequency of $0.01 \%-0.04 \%$. The recognition of this anomaly is important since it can be associated with serious complications. The aim of this study and review was to describe clinical and imaging features that help in establishing the diagnosis of this condition.

Methods We retrospectively reviewed all adult patients at the Cleveland Clinic Health System with the diagnosis of CPD between the years 2000 and 2015. Baseline clinical characteristics, clinical manifestations, ECG, transthoracic echocardiography (TTE), cardiac CT and cardiac magnetic resonance (CMR) images were reviewed.

Results Eight patients were included in the study. Sixtythree percent of patients were males with mean age at diagnosis of 48 years, $63 \%$ had a partial pericardial defect on the left side and right ventricular (RV) dilation on TTE. Three patients had CMR. Levocardia was present in all CMRs. One patient had greater than $60^{\circ}$ clockwise rotation and none of the CMRs showed ballooning of the left ventricular apex. One patient required surgical pericardioplasty. The remaining seven patients had a median follow-up of 17.3 months (5-144.9 months) and all remained asymptomatic.

Conclusion CPDs are more likely to be partial on the left side and patients often have RV dilation on the TTE and levocardia on CMR. Most patients remain stable and do not require surgical intervention. TTE and CMR play an important role in making the diagnosis of this anomaly.

\section{INTRODUCTION}

Congenital pericardial defect (CPD) is a rare clinical entity that was first described in 1793 by Matthew Baillie ${ }^{1}$ and has an estimated frequency of up to $0.04 \% .^{2}$ Although most of the cases are asymptomatic, the recognition of this anomaly is crucial, as it can be associated with serious complications such as ventricular herniation and sudden death. ${ }^{2}$ We aimed to describe the aetiology, clinical features, natural history, imaging findings and management options of this condition.

\section{Key questions}

What is already known about this subject?

- It is known that congenital pericardial defect (CPD) is a rare entity, but if present, may lead to serious clinical events including sudden death.

What does this study add?

- Our study adds the experience of a tertiary medica centre in diagnosing and managing patients with $\mathrm{CPD}$ and presents the outcomes of these cases.

How might this impact on clinical practice?

- Our study provides a systematic diagnostic and management approach for patients with CPD and can serve as a resource to evaluate and manage such cases in the future.

\section{METHODS}

Using the International Classification of Diseases (ICD-9) code, we identified all adults (>18 years old) at the Cleveland Clinic Health System with the diagnosis of CPD between 2000 and 2015. We searched for 'unspecified disease of pericardium' ICD-9 code: 423.9. Cases were further identified and verified by chart review. Baseline clinical characteristics, CPD type, associated anomalies, clinical manifestations, ECG, transthoracic echocardiography (TTE), cardiac CT and cardiac magnetic resonance (CMR) findings were obtained. Imaging diagnostic modalities were interoperated by a trained reader.

\section{RESULTS}

Eight patients were included in the study. Baseline characteristics are shown in table 1. Five patients $(63 \%)$ were males, with mean age at diagnosis of 48 years and the majority of patients $(63 \%)$ were asymptomatic. Symptomatic patients mostly complained of chest pain $(25 \%)$. Five patients $(63 \%)$ had a partial pericardial defect on the left side, three 
Table 1 Baseline characteristics and ECG findings

\begin{tabular}{|c|c|c|c|c|c|c|}
\hline Patient number & Age (years) & Gender & Symptoms & Type & Associated abnormalities & ECG (RBBB/RAD) \\
\hline 1 & 57 & Male & Asymptomatic & Complete absence & 0 & $+/+$ \\
\hline 2 & 46 & Male & Palpitations & Partial left absence & Pectus excavatum & $+/+$ \\
\hline 3 & 28 & Male & Asymptomatic & Partial left absence & Left ventricular diverticulum & $-/+$ \\
\hline 4 & 53 & Male & Chest pain & Complete absence & Pectus excavatum & $+/-$ \\
\hline 5 & 45 & Male & Chest pain & Complete absence & Pectus excavatum & $-1+$ \\
\hline 6 & 43 & Female & Asymptomatic & Partial left absence & 0 & $-1-$ \\
\hline 7 & 49 & Female & Asymptomatic & Partial left absence & 0 & $-1-$ \\
\hline 8 & 62 & Female & Asymptomatic & Partial left absence & 0 & $-/+$ \\
\hline
\end{tabular}

RAD, right axis deviation; RBBB, right bundle branch block.

patients $(38 \%)$ had pectus excavatum, and one patient had a left ventricular (LV) diverticulum in the anterio wall detected by both TTE and CMR. Two patients $(25 \%)$ had right bundle branch block (RBBB) and five patients $(63 \%)$ had right axis deviation (RAD) on ECG. TTE findings are presented in table 2. Five patients $(63 \%)$ had right ventricular (RV) dilatation, four patients $(50 \%)$ had levoposition of the heart, two patients $(25 \%)$ had paradoxical septal motion and two patients $(25 \%)$ had 'rocking motion' of the heart. Out of three patients who had CMR, three patients had levocardia, one patient had greater than $60^{\circ}$ clockwise rotation (CWR) and none of the patients had ballooning of the left ventricle (LV) apex. Other CMR findings were biatrial prominence, large atrial appendage extending anteriorly next to the central pulmonary artery in patient (three). One patient had cardiac CT which showed interposition of the lung between the great vessels. One patient required surgical pericardioplasty (patient two) which was done due to consistent palpitations and chest pain. Although pericardioplasty was done, patient's symptoms did not completely resolve, and patient continued to complain of palpitations, chest pain and dizziness. The remaining seven patients had a median follow-up of 17.3 months
(5-144.9 months) and all remained clinically asymptomatic.

The diagnosis of CPD was detected by TTE in all cases and was confirmed with CMR in three cases and with CT in one case. Out of the five asymptomatic cases we reported, one case was diagnosed incidentally (patient three) in our centre. In this case, TTE followed by CMR were done due to premature ventricular contractions noted in ECG. The other four cases were referred to our centre and it was unclear if CPD was found incidentally at the time of diagnosis.

\section{DISCUSSION \\ Etiology}

Embryologically, the pericardium forms after fusion of the pleuropericardial folds by the end of the fifth week. Any failure of the folds to fuse causes CPD. ${ }^{3}$ There are two main theories explaining the failure of fusion: first, the heart enlarges and stretches the pleuropericardial folds before they have the chance to fuse, causing the defects. ${ }^{3}$ The second theory is a premature atrophy of the left duct of Cuvier (common cardinal veins) supplying the pleuropericardial folds, which may lead to persistence of the

\section{Table 2 Echocardiographic, CT and CMR data}

\begin{tabular}{|c|c|c|c|c|c|c|c|c|}
\hline \multicolumn{5}{|c|}{ Echocardiography } & \multicolumn{3}{|l|}{ CMR } & \multirow{2}{*}{$\begin{array}{l}\text { CT } \\
\text { Interposition } \\
\text { of the left lung } \\
\text { between the } \\
\text { great vessels }\end{array}$} \\
\hline $\begin{array}{l}\text { Patient } \\
\text { number }\end{array}$ & $\begin{array}{l}\text { RV } \\
\text { dilation }\end{array}$ & $\begin{array}{l}\text { Levoposition } \\
\text { of the heart }\end{array}$ & $\begin{array}{l}\text { Paradoxical } \\
\text { septal motion }\end{array}$ & $\begin{array}{l}\text { 'Rocking } \\
\text { motion' of } \\
\text { heart }\end{array}$ & Levocardia & $\begin{array}{l}\text { Ballooning } \\
\text { of LV apex }\end{array}$ & $\begin{array}{l}>60^{\circ} \\
\text { clockwise } \\
\text { rotation }\end{array}$ & \\
\hline 1 & - & + & - & - & + & - & + & N/A \\
\hline 2 & + & + & + & - & $\mathrm{N} / \mathrm{A}$ & $N / A$ & $\mathrm{~N} / \mathrm{A}$ & $\mathrm{N} / \mathrm{A}$ \\
\hline 3 & + & - & - & - & + & - & - & $\mathrm{N} / \mathrm{A}$ \\
\hline 4 & + & - & + & + & $\mathrm{N} / \mathrm{A}$ & $\mathrm{N} / \mathrm{A}$ & $\mathrm{N} / \mathrm{A}$ & $\mathrm{N} / \mathrm{A}$ \\
\hline 5 & - & - & - & - & $N / A$ & $N / A$ & $\mathrm{~N} / \mathrm{A}$ & $\mathrm{N} / \mathrm{A}$ \\
\hline 6 & + & + & - & + & $\mathrm{N} / \mathrm{A}$ & $\mathrm{N} / \mathrm{A}$ & $\mathrm{N} / \mathrm{A}$ & + \\
\hline 7 & + & - & - & - & + & - & - & N/A \\
\hline 8 & - & + & - & - & $\mathrm{N} / \mathrm{A}$ & $N / A$ & $N / A$ & $\mathrm{~N} / \mathrm{A}$ \\
\hline
\end{tabular}

CMR, cardiomagnetic resonance; LV, left ventricular;N/A, not applicable; RV, right ventricle. 
embryonic pleuropericardial foramen. The latter theory explains why left pericardial defects are more common since the right duct of Cuvier develops into the superior vena cava (SVC), ensuring the closure of the right pleuropericardial membrane. ${ }^{45}$ Other reports suggested that some defects may be due to a tear in the pleuropericardial membrane rather than failure of the pleuropericardial foramen to close. ${ }^{6}$ Little evidence of hereditary pattern and familial occurrence is reported. ${ }^{7}$

Approximately one-third of congenital absence of pericardium cases are associated with other congenital heart abnormalities such as mitral stenosis, tetralogy of Fallot, atrial septal defect (ASD), bicuspid aortic valve, diaphragmatic hernia, an anomaly of the aortic arch leading to type A aortic dissection, annuloaortic ectasia, marfanoid features, congestive heart failure secondary to aortic insufficiency and myocardial non-compaction. ${ }^{8-11}$ The defect due to aberrant development of the septum transversum is associated with a defect in the central tendon of the diaphragm. ${ }^{12}$ If diaphragmatic hernia exists, it is usually associated with absence of the inferior pericardium. ${ }^{13}$ Early atrophy of the left and right duct of Cuvier may lead to abnormal budding of the lung, leading to bronchogenic cysts, sequestrated lungs and aberrant lobes. ${ }^{12}$

\section{Clinical manifestations}

Consistent with the literature, our study showed male predominance $(63 \%){ }^{12}$ Partial left pericardial defect was more common $(63 \%)$, followed by complete absence of pericardium (37\%). Right-sided and bilateral partial absence of the pericardium are extremely rare with a reported frequency of the right partial defect of less than $1 \% .^{14}$

CPD can mimic other conditions such as acute coronary syndromes, cardiac aneurysms, ASD, tumours of the lung and heart, mitral valve disease, pulmonic stenosis, idiopathic dilation of the pulmonary artery and hilar lymphadenopathy. ${ }^{12}$ In addition, CPD was found with a rare concomitant defect of vascular ring created by rightsided aortic arch with aberrant origin of the left subclavian artery and Kommerell's diverticulum. CPDs have also been noted in patients with VATER syndrome and Pallister-Killian syndrome. ${ }^{12} 15$ ASD shares many clinical features and ECG findings with CPD, such as systolic ejection murmur, wide split of S2 and RBBB ECG pattern. ${ }^{16}$ Both conditions can be differentiated by the positional changes during TTE in patients with CPD. ${ }^{16}$ The majority of the cases are asymptomatic and are frequently diagnosed incidentally postmortem ${ }^{1}$ or when undergoing cardiac surgery. ${ }^{2}$

Symptomatic patients may have chest pain, shortness of breath or palpitations, with chest pain being the most predominant symptom in up to $33 \%$ of patients. ${ }^{13}$ Other symptoms include sweating, dyspnoea, circulatory collapse and syncope. ${ }^{17}$ Twenty-five percent of our cohort had chest pain as the main complaint. Occasionally, left arm movement, breathing, or turning from side to side effects the discomfort. ${ }^{17}$ The cause of chest pain has been presumed to be due to torsion of great vessels and the lack of a cushioning effect of the pericardium, allowing the heart to pound freely on the overlying lung or chest and tension in the pleuropericardial adhesions. ${ }^{12} 18$ Trepopnea, which is the presence of dyspnoea when laying on one side but not the other, is a unique finding in patients with partial defects. ${ }^{12}$ Symptoms may be worse in the left lateral position because of volume loading of the ventricles especially the right ventricle. ${ }^{12}$ Furthermore, a large left-sided pericardial defect may generate coronary artery insufficiency and fatal cardiac herniation. ${ }^{19}$ The most likely mechanism for syncope is a neural reflex triggered by intermittent herniation, either of the appendage of atrial tissue with vagally mediated bradycardia or hypotension. ${ }^{17}$ Sinus sick syndrome has been reported and is believed to be secondary to an enhanced vagal tone. ${ }^{20}$ It is positional as the heart rate normalises in the right lateral position and it usually responds to atropine. ${ }^{20}$

Pericarditis or haemorrhage from a tightly strangulated atrial appendage was also reported. ${ }^{19}$ The risk of sudden death in this scenario was attributed to the herniation of the LV or atrial appendage (AA) and involvement of the left circumflex coronary artery. ${ }^{21}$ Left AA protrusion might also cause persistent atrial fibrillation. ${ }^{22}$ Leftsided pneumothorax with consequent protrusion of the heart into left thoracic cavity was also described. ${ }^{23}$ Traumatic rupture of the tricuspid valve chordae tendineae may occur in partial defects, as without a complete pericardium, the heart may be prone to torsion beyond its normal range under cardiac contusion, causing rupture of the chordae tendineae. ${ }^{24}$

Cardiac displacement and increased mobility impose an increased risk for traumatic type A aortic dissections. ${ }^{12}$ Acute type A dissection associated with hemothorax and with little pericardial effusion indicates existence of a pericardial defect. ${ }^{9}$ If an acute dissection occurs in a patient with an undiagnosed CPD, the diagnosis of dissection may not be recognised due to the absence of significant pericardial effusion. ${ }^{9}$

\section{Diagnosis}

The physical examination (PE) and ECG in patients with partial defects are usually normal. ${ }^{13}$ However, PE may be significant for displacement of the apical impulse to the left, mid, or anterior axillary lines. ${ }^{25}$ It may also show pectus excavatum, pericardial rub, left sternal edgepulmonic ejection murmur, systolic mitral murmur, and apical or left sternal edge diastolic murmur. ${ }^{1726}$ Thirtyeight percent of our cases had pectus excavatum.

In cases of absence of the left pericardium, ECG shows RAD, incomplete RBBB pattern, leftward displacement of the transitional zone in the precordial leads, peaked $\mathrm{P}$ waves, postural changes in the QRS vector, and bradycardia. ${ }^{25} 27$ Sixty-three percent of our cases had RAD (figure 1). Compression of the coronary circulation by the rim of the defect may cause abnormality of repolarisation. ${ }^{17}$ 

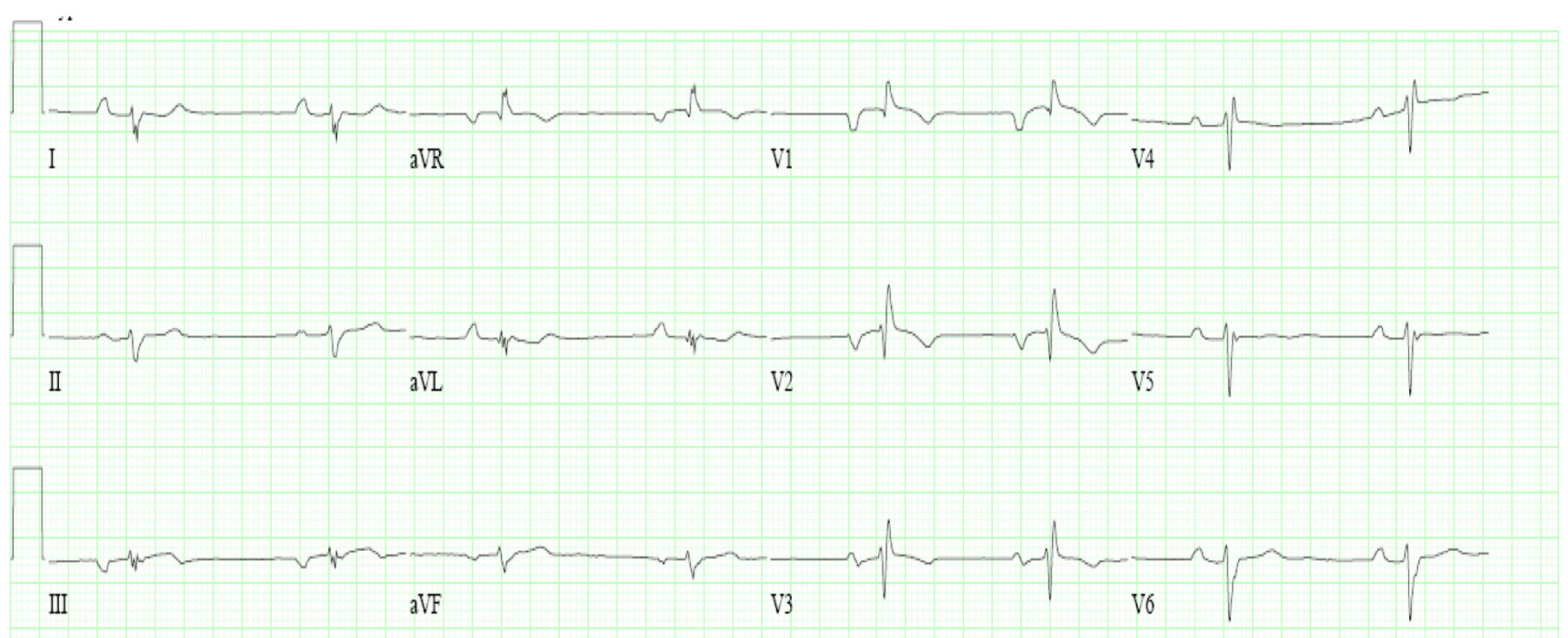

Figure 1 Typical ECG of patient with absent pericardium showing right axis deviation, incomplete RBBB and right ventricular hypertrophy. RBBB, right bundle branch block.

Chest X-ray (CXR) shows leftward shifted cardiac silhouette, elongated left heart border, radiolucency between the left hemidiaphragm and the base of the heart, ${ }^{25}$ a radiolucent cleft between the ascending aorta and the main pulmonary artery ${ }^{5}$ and cardiomegaly in $50 \%$ of cases, which may be partially due to the slight rotation of the heart into the left chest. ${ }^{13}$ About one-third of defects are suspected only after a chest film is made for unrelated reason. ${ }^{17}$ The space between the aorta and the main pulmonary artery may appear widened due to the presence of the lung tissue between these two vessels, the so called 'Snoopy Sign' (figure 2).$^{28}$ This also results in sharp demarcation of the pulmonary artery. ${ }^{13}$

One of the first findings appreciated on echocardiography in patients with the complete absence of the pericardium is that the standard views may not apply. ${ }^{129} \mathrm{On}$

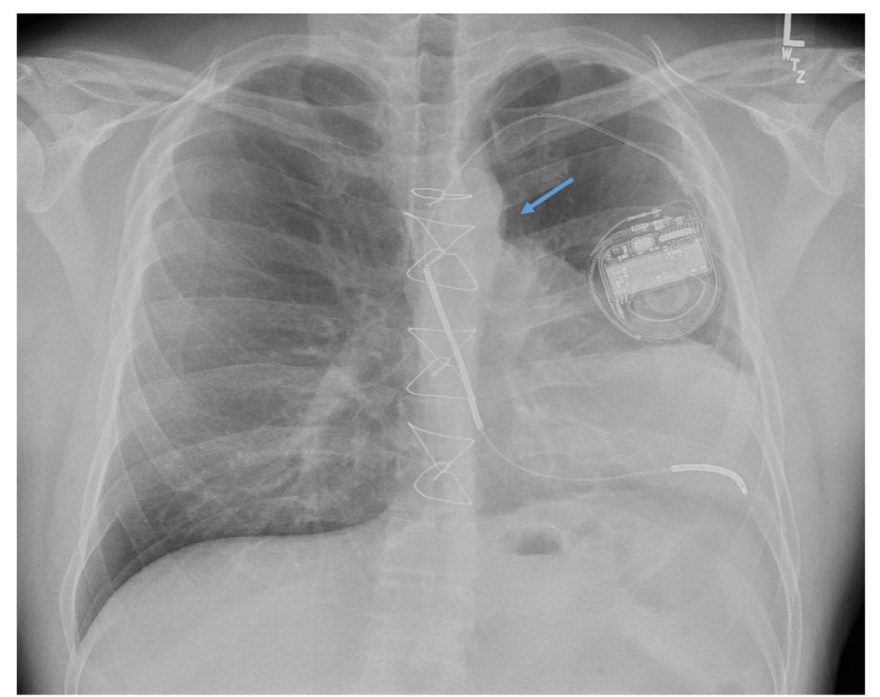

Figure 2 Chest X-ray showing heart displacement in the left hemithorax and a sharp aortopulmonary window (arrow). the traditional left parasternal view, more of the right ventricle is seen due to the left shift of the heart and, as a result, the patient may be falsely diagnosed with $\mathrm{RV}$ dilatation (figure $3 \mathrm{~A}$ ). ${ }^{12}$ In the apical window, there is marked lateral displacement of the heart and the appearance of compressed atria with the patient in the left lateral decubitus position (figure $3 \mathrm{~B}) .{ }^{12}$ As a result, some find that images are better obtained in supine position rather than left lateral decubitus. ${ }^{12}$ Exaggerated movement of the heart may also be seen during stress echocardiography examination. ${ }^{12}$ The paradoxical movement can be cancelled in the right lateral position since the right-sided pericardium restricts the abnormal shift of the heart. ${ }^{20}$ Cardiac hypermobility and abnormal ventricular septal wall 'rocking motion' are described in most patients. ${ }^{29}$ The typical findings with the complete

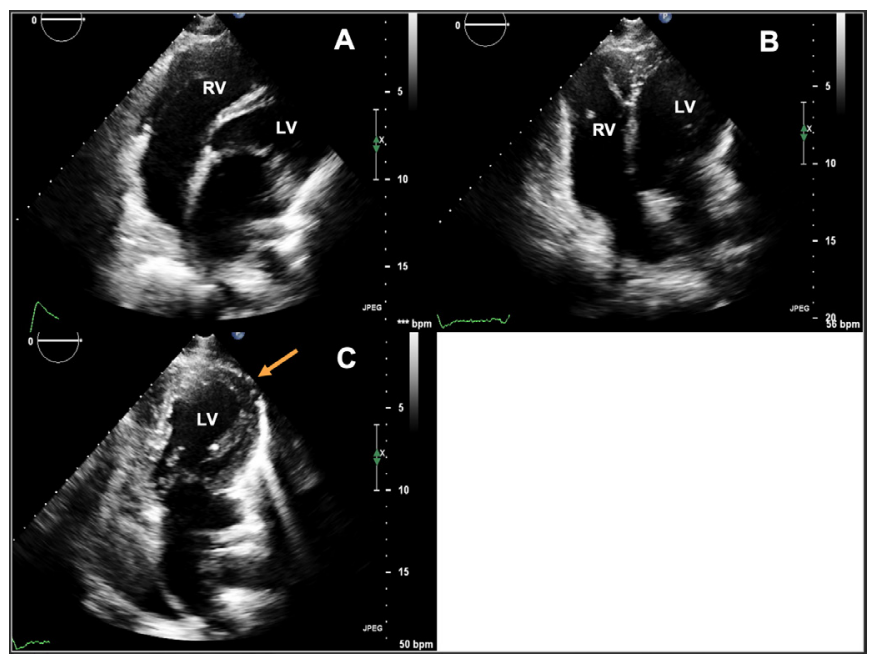

Figure 3 Apical four-chamber view showing RV dilation (A and B) and levoposition of the LV (arrow) (C). LV, left ventricular; $\mathrm{RV}$, right ventricular. 
absence of the pericardium are a 'teardrop' shape of the heart, a bulbous LV and elongated atria in the apical fourchamber view, because of the absence of normal tethering applied by the normal pericardium. ${ }^{12}$ In addition, there is exaggerated cardiac motion, especially of the LV posterior wall. ${ }^{12}$ In cases of LV herniation, marked thickening of the apical LV may be seen and it is due to oedema from venous coronary obstruction. ${ }^{12}$ The characteristic findings on m-mode include RV enlargement and abnormal septal motion. The paradoxical motion of the interventricular septum is due to the exaggerated posterior LV wall motion which produces anterior displacement of the interventricular septum. ${ }^{12}$ Evaluation of speckle tracking shows decreased LV torsion in patients with the absence of the pericardium. However, longitudinal, radial and circumferential strain and strain rates showed no significant abnormalities in patients with pericardial defects compared with controls, suggesting that the absence of the pericardium does not impact regional LV myocardial function. ${ }^{12}$ Enlarged RV and hypertrophied right atrium with severe tricuspid regurgitation due to traction of the chordal structures could be seen in patients with rightsided defects. ${ }^{12}$ Sixty-three percent of our cohort had RV dilation and 25\% had 'rocking motion' of heart.

The most common sites of pericardial defects correlate with the locations that are not ideally visualised on chest CT. ${ }^{12}$ In nearly all cases, the pericardium may be visualised as a clear, thin line, external to the subepicardial adipose tissues that surround the myocardium. ${ }^{25}$ Prominence of the main pulmonary artery and interposition of the left lung between the great vessels is well described on CT. ${ }^{13}$ Tethering of the right pericardium to the anterior chest wall by sternopericardial ligaments is seen on axial CT. ${ }^{30}$ Leftward cardiac displacement is usually seen with complete left pericardial disease. ${ }^{12}$ This swinging of the heart may cause motion artefact when performing chest CT that may lead to misdiagnosis of other conditions such as pulmonary embolism. ${ }^{31}$

CMR is the best way to show both the absence of pericardium and the defect's relationship to the underlying structures. ${ }^{17}$ The isolated protrusion of the AA, coupled with indentation of the ventricle by the defect's rim is considered pathognomonic (figure 4). ${ }^{17}$ The 'tongue' of the lung tissue interposing between the main pulmonary artery and aorta is the most consistent diagnostic feature by both cardiac CT and CMR, including patients with partial or complete absence of pericardium. ${ }^{8}$ Since imaging at the level of the atria and ventricles requires pericardial fat or pericardial fluid for tissue differentiation, a paucity of fat, particularly in children, may prevent definition of the pericardium. ${ }^{17}$ CMR will also be able to differentiate between left atrial aneurysm and pericardial diseases. Although CMR can generally identify the pericardium, visualisation of the pericardium varies with location. As a result, lack of visibility of the pericardium on CMR does not prove the absence of the pericardium, and can lead to an erroneous diagnosis in up $10 \%$ of patients. ${ }^{12}$ CWR in CMR is another quantitative parameter derived by CMR. This angle, which is significantly increased in left pericardial absence, may be used to quantitatively measure the degree of levorotation of the LV. A higher CWR angle means backward deviation of the main cardiac axis. A cut-off of $>60^{\circ}$ had moderately good sensitivity and optimal specificity to distinguish between patients with the absence of left pericardium. ${ }^{32}$ Also, in patients with pericardial defects, the heart was located deeper within the chest at end-diastole than healthy subjects. ${ }^{32}$ CWR with a cut-off of $>60^{\circ}$ distinguishes left absence of pericardium from RV overload. ${ }^{32}$ These conclusions can also be applied to cardiac CT. ${ }^{32}$ All patients who had CMR in our series had levocardia and one patient had $>60^{\circ} \mathrm{CWR}$.

In coronary angiography, both dynamic migratory obstruction and diastolic pressure alternans suggest pericardial defect. ${ }^{33}$ This finding was presumed to occur because of the excessive hypermobility with beat-to-beat, to-and-fro swinging of the heart and distortion of the ventricular shaped volume during each cycle coupled with an abnormal interventricular septal movement. ${ }^{34}$ In patients with partial defects and acute chest pain, ST

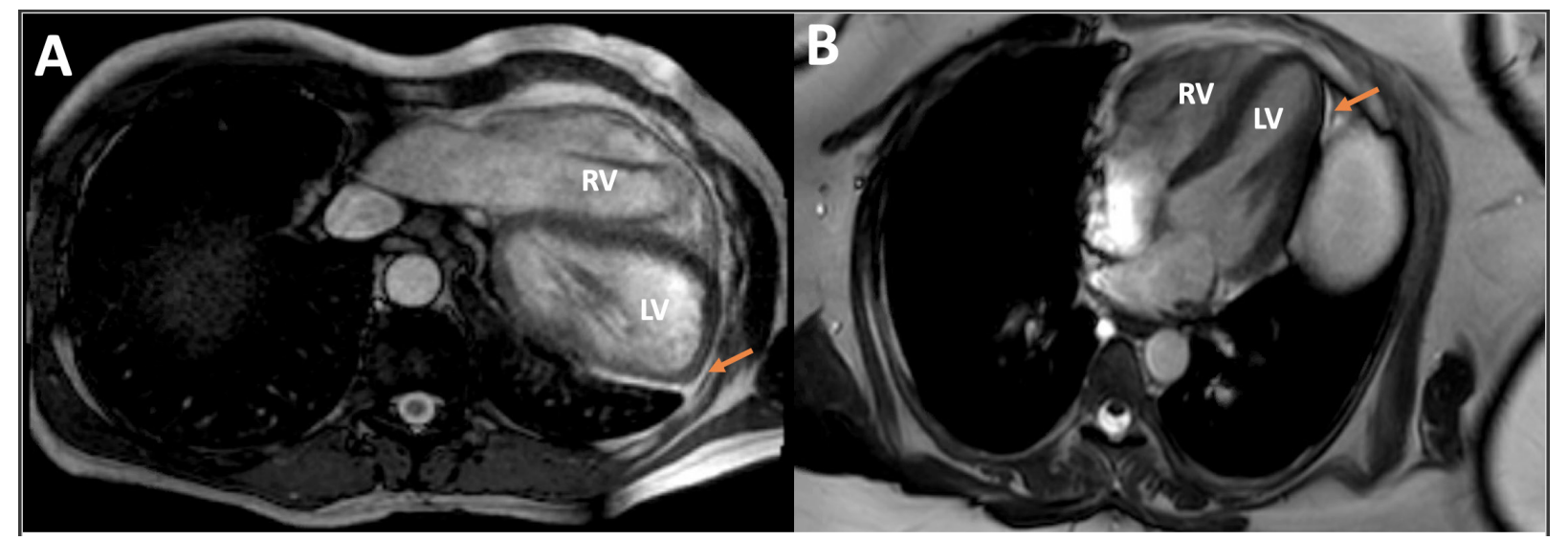

Figure 4 Cardiac magnetic resonance imaging showing significant displacement of the heart into the left hemithorax with complete absence of the pericardium (A) (arrow) compared with normal pericardial position (B) (arrow). LV, left ventricular; RV, right ventricular. 


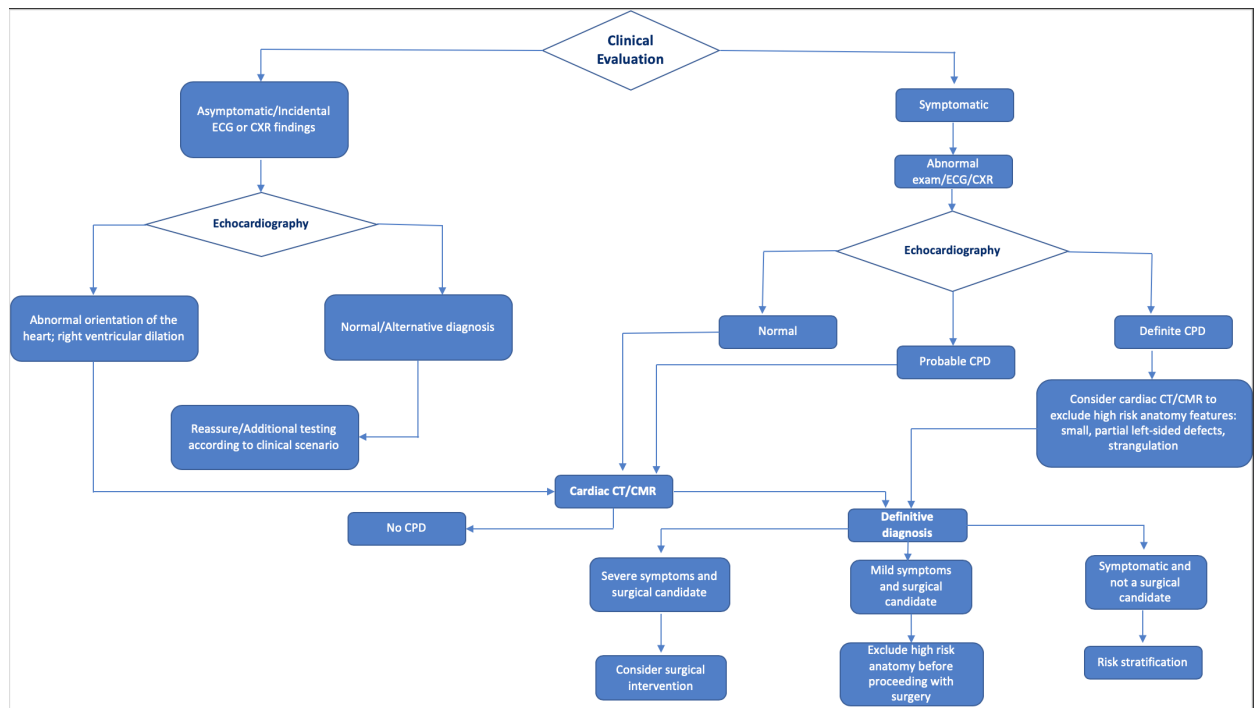

Figure 5 Systematic approach for the diagnosis and management of patients with suspected congenital pericardial defect, incorporating multimodality cardiovascular imaging. CPD, congenital pericardial defect; CMR, cardiac magnetic resonance; CXR, Chest X-ray.

segment elevation may be seen on ECG. Cardiac catheterisation in these cases can show a unique angiographic finding of normal calibre coronaries with good flow followed by an abrupt focal kink or angulation in the arteries which is secondary to external compression of coronary arteries by the pericardial rim. ${ }^{12}$ Finally, thoracoscopy may be the best of all confirmatory methods and has the advantage of being able to deliver therapeutic intervention at the time of diagnosis. ${ }^{17}$ Historically, artificial pneumothorax was used to demonstrate the absence of pericardium, but it is not as reliable in defining the anatomy and extension of the defect. Due to discomfort and morbidity associated with thoracoscopy and artificial pneumothorax, they are rarely used nowadays and in current practice, its description is of historic interest. ${ }^{17}$

\section{Treatment}

Prognostically, patients with the complete absence of pericardium have similar LV function and have the same life expectancy compared with patients with normal pericardium. ${ }^{12}$ For patients with complete bilateral or complete left-sided absence of the pericardium, no treatment is indicated. ${ }^{12}$ On the other hand, closing the partial defect may restore the heart's natural barrier for infection. ${ }^{17}$ Moderate-sized defects have a tendency for herniation and cardiac strangulation, so, prophylactic repair is recommended in such cases. ${ }^{2}$ If the defect circumscribes part of the LV, especially the body or apex, surgery is warranted, even if the coronary circulation is not compromised. ${ }^{17}$ However, if the defect is confined to the upper left heart border, permitting only the appendage to protrude, the condition is not particular hazardous and incarceration rarely occurs. ${ }^{17} \mathrm{Xu}$ and colleagues suggested a management strategy in patients with suspected CPD. Cardiac CT and/or CMR should be done in all symptomatic patients to exclude other alternative diagnoses. Non-surgical candidates should go through risk stratification. If patients have mild symptoms and are surgical candidates, high risk anatomy should be excluded before proceeding with surgery; and if patients have severe symptoms and are surgical candidates, surgical intervention should be considered (figure 5). ${ }^{26} 35$

In many cases, all that is needed is pericardiectomy, ${ }^{2}$ or division of adhesions. ${ }^{8}$ If the AA herniates through a partial pericardial defect, the defect may be closed with a patch. ${ }^{2}$ The most commonly selected procedure for this anomaly is direct or patch closure of the defect with or without left atrial appendectomy through a thoracotomy or a median sternotomy. ${ }^{19}$ Thoracoscopic procedures are safe, minimally invasive and inexpensive compared with thoracotomy or median sternotomy, particularly, when it is performed prophylactically. ${ }^{819}$ It should be noted that coronary artery narrowing may remain even after generous pericardiectomy. ${ }^{17}$ If the defect is associated with the defect in the central tendon of the diaphragm, this should be surgically corrected, as these defects are associated with permanent risk of a diaphragmatic hernia. ${ }^{17}$ In cases of small defects that are associated with pneumothorax and the inflated lung cannot push the heart back to the mediastinum from the thoracic cavity, surgical closure or enlargement may be required to alleviate complications such as herniation and entrapment of the cardiac chamber. ${ }^{23}$

Complications of surgical intervention include acute SVC syndrome ${ }^{36}$ and left phrenic nerve injury (LPNI). ${ }^{17}$ LPNI is a potential complication with any approach as the nerve may both run along the anteromedial rim of the defect and may be found behind, or even stranding the defect. ${ }^{17}$ In case of acute SVC syndrome, cutting open of the pericardium relieves the obstruction. ${ }^{36}$ Only one patient of our cohort required surgical pericardioplasty and the other seven patients remained clinically asymptomatic at a median follow-up of 17.3 months (5-144.9 months). 


\section{Limitations}

Our study has several limitations. First, it is a retrospective study, therefore, our results should be interpreted in this concept. Second, our sample size is small, however, CPD is a rare entity and we included all patients who were referred to our pericardial centre between 2000 and 2015. Third, although we used ICD-9 to identify patients with 'unspecified disease of pericardium', further identification and verification to CPD cases were performed by chart review. Finally, as few of our cases were referred from other institutions, we were not able to track some cardiovascular images that were not done in our institution.

\section{CONCLUSION}

In conclusion, CPD is a rare condition with partial left pericardial absence the most common type. Patients are often asymptomatic, and the diagnosis is mostly made incidentally. If patients are symptomatic, they are more likely to have chest pain. TTE plays an important role in making the diagnosis, however, CMR is the gold standard. Patients with complete bilateral or complete left pericardial absence are unlikely to need treatment; on the other hand, partial pericardial absence needs to be treated to avoid critical complications.

\section{Twitter Mohamed Khayata @mdkhayata}

Contributors All authors contributed to this manuscript.

Funding The authors have not declared a specific grant for this research from any funding agency in the public, commercial or not-for-profit sectors.

Competing interests None declared.

Patient consent for publication Not required.

Provenance and peer review Not commissioned; externally peer reviewed.

Data availability statement All data relevant to the study are included in the article or uploaded as supplementary information.

Open access This is an open access article distributed in accordance with the Creative Commons Attribution Non Commercial (CC BY-NC 4.0) license, which permits others to distribute, remix, adapt, build upon this work non-commercially, and license their derivative works on different terms, provided the original work is properly cited, appropriate credit is given, any changes made indicated, and the use is non-commercial. See: http://creativecommons.org/licenses/by-nc/4.0/.

ORCID iD

Mohamed Khayata http://orcid.org/0000-0001-8116-4311

\section{REFERENCES}

1 Southworth $\mathrm{H}$, Stevenson CS. Congenital defects of the pericardium. Arch Intern Med 1938;61:223-40.

2 Van Son JA, Danielson GK, Schaff HV, et al. Congenital partial and complete absence of the pericardium. Mayo Clin Proc 1993;68:743-7.

3 Koo CW, Newburg A. Congenital absence of the right pericardium: embryology and imaging. J Clin Imaging Sci 2015;5:12.

4 Bogaert J, Francone M. Pericardial disease: value of CT and MR imaging. Radiology 2013;267:340-56.

5 Pickhardt PJ. Congenital absence of the pericardium confirmed by spontaneous pneumothorax. Clin Imaging 1998;22:404-7.

6 Kaneko Y, Okabe H, Nagata N. Complete left pericardial defect with dual passage of the phrenic nerve: a challenge to the widely accepted embryogenic theory. Pediatr Cardiol 1998;19:414-7.

7 Palau P, Domínguez E, García-González P, et al. Isolated partial congenital absence of the pericardium: a familial presentation. Can $J$ Cardiol 2016;32:1039.e1-1039.e2.
8 Gatzoulis MA, Munk MD, Merchant N, et al. Isolated congenital absence of the pericardium: clinical presentation, diagnosis, and management. Ann Thorac Surg 2000;69:1209-15.

9 Furui M, Ohashi T, Hirai Y, et al. Congenital pericardial defect with ruptured acute type A aortic dissection. Interact Cardiovasc Thorac Surg 2012;15:912-4.

10 Ekeke CN, Daniels C, Raman SV, et al. Annuloaortic ectasia in a patient with congenital absence of the left pericardium. Ann Thorac Surg 2013;96:2243-5.

11 Hojjati MR, Rozo JC, Nazeri A, et al. A rare pairing: myocardial noncompaction and congenital absence of pericardium. Tex Heart Inst J 2013:40:500-1.

12 Shah AB, Kronzon I. Congenital defects of the pericardium: a review. Eur Heart J Cardiovasc Imaging 2015;16:821-7.

13 Faridah Y, Julsrud PR. Congenital absence of pericardium revisited. Int J Cardiovasc Imaging 2002;18:67-73.

14 Ikeda K, Kimura N, Abe T. Right-Side congenital pericardial defect associated with ischemic heart disease. In: Japanese Journal of thoracic and cardiovascular surgery. , 2002: 50, 116-8.

15 Sani ZA, Savand-Roomi Z, Vojdanparast M, et al. Congenital partial absence of the pericardium presenting with a rare concurrent abnormality of vascular ring diagnosed by cardiac magnetic resonance imaging. Adv Biomed Res 2016;5:203.

$16 \mathrm{Kim} \mathrm{MJ}$, Kim H-K, Jung J-H, et al. Echocardiographic diagnosis of total or left congenital pericardial absence with positional change. Heart 2017;103:1203-9.

17 Bennett KR. Congenital foramen of the left pericardium. Ann Thorac Surg 2000;70:993-8.

18 Chung JH, Choi RK, Oh SS, et al. A case of partial congenital pericardial defect presenting as acute coronary syndrome. Korean Circ J 2013;43:845.

19 Yamagishi T, Ishikawa S, Yoshida I, et al. Thoracoscopic closure of a congenital partial pericardial defect. Surg Today 1997;27:874-5.

20 Hano O, Baba T, Hayano M, et al. Congenital defect of the left pericardium with sick sinus syndrome. Am Heart J 1996;132:1293-5.

21 Rusk RA, Kenny A. Congenital pericardial defect presenting as chest pain. Heart 1999;81:327-8.

22 Lee H, Jeong DS, Kim IS, et al. Persistent atrial fibrillation related to a congenital pericardial defect and left atrial appendage herniation. Korean J Thorac Cardiovasc Surg 2015;48:429-31.

23 Sugiura Y, Matsusaka Y, Nemoto E, et al. Incidental finding of congenital pericardial and mediastinal pleural defect by pneumothorax in an adult. Radiography 2015;21:e81-4.

24 Higashikawa M, Nishio M, Kanamori T, et al. Traumatic tricuspid regurgitation associated with congenital partial pericardial defect. Jpn Circ J 1997;61:358-60.

25 Salem DN, Hymanson AS, Isner JM, et al. Congenital pericardial defect diagnosed by computed tomography. Cathet Cardiovasc Diagn 1985;11:75-9.

26 Xu B, Betancor J, Asher C, et al. Congenital absence of the pericardium: a systematic approach to diagnosis and management. Cardiology 2017;136:270-8.

27 Enad JG. Partial absence of pericardium in an endurance athlete. A case report. J Sports Med Phys Fitness 2002;42:89-91.

28 Panagiotopoulos N, Barnard J, Wells F. The Snoopy sign. Eur J Cardio-Thoracic Surg 2014;45:586

29 Flosdorff P, Paech C, Riede F-T, et al. Odd acoustic window and elongated ventricles: echocardiographic diagnosis of congenital absence of the pericardium. Pediatr Cardiol 2012;33:1220-1.

30 Vesely T, Julsrud PR. Congenital absence of the pericardium and its relationship to the ligamentum arteriosum. Surg Radiol Anat 1989.

31 Tariq S, Mahmood S, Madeira S, et al. Congenital complete absence of pericardium masquerading as pulmonary embolism. Heart Views 2013;14.

32 Macaione F, Barison A, Pescetelli I, et al. Quantitative criteria for the diagnosis of the congenital absence of pericardium by cardiac magnetic resonance. Eur J Radiol 2016;85:616-24.

33 Nguyen DQ, Wilson RF, Bolman RM, et al. Congenital pericardial defect and concomitant coronary artery disease. Ann Thorac Surg 2001;72:1371-3.

34 Oki T, Tabata T, Yamada H, et al. Cross sectional echocardiographic demonstration of the mechanisms of abnormal interventricular septal motion in congenital total absence of the left pericardium. Heart 1997;77:247-51.

35 Lopez D, Asher CR. Congenital absence of the pericardium. Prog Cardiovasc Dis 2017;59:398-406.

36 Mohite PN, Rana SS, Singh J, et al. Acute superior vena cava obstruction due to tight pericardial closure following congenital defect repair. J Cardiovasc Dis Res 2012;3:135-7. 